\title{
Monográfico II
}

\section{HISTORIOGRAFIAA Y PODER EN COLOMBIA.} UN SIGLO DE ESCRITURAS

\author{
Coordinado por \\ Patricia Cardona Z.
}





\section{Presentación / Presentation}

Los artículos que conforman este monográfico son una muestra representativa de los desarrollos de la historiografía colombiana, un ámbito de trabajo vigoroso que ha logrado importantes entrecruzamientos entre la historia cultural, la historia conceptual, la historia política la historia intelectual, la teoría de la historia, y la hermenéutica. Llama la atención la revisión que hacen los artículos aquí presentados de la historia política de Colombia, en una temporalidad que va desde fines del siglo XVIII hasta las primeras décadas del siglo XX, pero esta vez con los ojos puestos en su configuración historiográfica, en las condiciones históricas de producción, interpretación, uso y sentido de esos textos.

El monográfico propone la reescritura de algunos de los hechos más representativos de la historia política de Colombia en una perspectiva renovada, que incluye nuevas metodologías de análisis, nueva documentación y, sobre todo, una visión que preguntándose por los usos del pasado, ha develado las relaciones intrínsecas entre poder, escritura e historia. De este modo se hace evidente que los archivos se enriquecen con un delicado trabajo de análisis, intepretación y comprensión, solamente posible con un buen recaudo teórico. La teoría no es una camisa de fuerza que se impone al material empírico, sino más bien, un camino de indagación que adquiere relevancia gracias a él.

El monográfico está formado por siete artículos que se preguntan por las relaciones entre escritura, historia y política; en él participan historiadores de distintas ciudades colombianas, pero unidos por un interés común; el estudio de grupos letrados en Colombia y sus relaciones con la política y la configuración de un relato histórico en el país.

Hemos definido una organización más o menos cronológica; empezamos el monográfico con un texto del profesor Renán Silva que se ocupa de las relaciones entre arte y sociedad, vistas, fundamentalmente, en los textos del ilustrado Francisco José de Caldas, figura clave no sólo del movimiento ilustrado, sino también en el proceso de emancipación. Sigue el monográfico explorando las nociones de pasado, tiempo e historia en la prensa publicada en plena efervescencia de las revoluciones de independencia. El profesor 
Rodrigo García estudia, con herramientas de la historia conceptual, los cambios semánticos en las nociones relacionadas con la historicidad. Rafael Acevedo, en su artículo, se ocupa de la historia trágica de la conquista como justificación y al tiempo explicación de lucha por la independencia de la Nueva Granada de la metrópoli española. Patricia Cardona Z. analiza la importancia del pasado patrio y su actualidad en las disputas ideológicas y políticas en Colombia en 1872, en el marco de la nacionalización del 20 de julio como efeméride de su independencia. El artículo de Gilberto Loiza Cano propone una mirada sobre el siglo XIX a partir de lo que él denomina regularidad discursiva, esto es, un modo característico de producir enunciados que contribuyen a dotar de identidad un período largo de la historia. David Murillo aborda las estrategias culturales de diplomacia chilena en Colombia encarnadas en José A. Soffia, quien además de sus funciones diplomáticas adelantó iniciativas culturales con la elite letrada colombiana, cercana al proyecto conservador denominado Regeneración. El último artículo, escrito por David Samacá, estudia la Academia de Historia de Colombia y las negociaciones y disputas jurídicas que enmarcaron la compilación de los papeles del Francisco de Paula Santander, necesarios para la legitimación de la república.

Esperamos que los textos reunidos aquí contribuyan a ampliar la perspectiva sobre la historiografía en general y sobre la historiografía colombiana en particular. Este es un sendero por el que se transita gracias al trabajo mancomunado de disciplinas, teorías, enfoques y metodologías diversas, a la consolidación de una comunidad de estudiosos que confrontan y comparten sus hallazgos; que dan a conocer sus hipótesis para precisar el conocimiento histórico e historiográfico y para delimitar sus contornos. Encontrará el lector textos que comportan un trabajo histórico riguroso, enmarcado en las pesquisas documentales y en el desarrollo teórico como herramienta para interpretar y comprender el pasado; todas ellas prácticas inherentes al oficio apasionante pero difícil de historiador.

Patricia Cardona Z. Editora del monográfico azuluaga@eafit.edu.co Universidad Eafit (Medellín, Colombia) 